\title{
PROJETOS DE LETRAMENTO NA ESCOLA: DE SUA RELEVÂNCIA COMO PONTO DE PARTIDA E DE CHEGADA DA LEITURA E DA ESCRITA NO MUNDO DIGITAL E NO MUNDO DO TRABALHO
}

Literacy projects in school: its relevance as a starting point and the arrival of reading and writing in the digital world and in the world of work

Antonio Artur Silva Cantuário ${ }^{1}$

RESUMO: A escola parece não ter acompanhado as mudanças sociais no modo de interagir das pessoas. No campo do trabalho é comum que indivíduos percam oportunidades de emprego por não saberem redigir um currículo e/ou como usar as redes digitais para se conectar com empresas ou buscar oportunidades nesse sentido, pois possuem fragilidades no uso da leitura e da escrita no mundo do trabalho e no mundo digital. Diante dessa problemática, este estudo apresenta uma discussão sobre a relevância de aplicação de projetos de letramento em sala de aula de Língua Portuguesa, com foco nas práticas de leitura e escrita da esfera profissional em interface com o ambiente digital. A proposta ancora-se teoricamente nas concepções de Kleiman (2007), Soares (2009), Tfouni (1994) e Rojo (2012) sobre as concepções de alfabetização e letramento; Coscarelli (2011), Goulart (2011), Lévy (1999) e Xavier (2010), sobre as práticas de letramento digital e ensino; e Bakhtin (2011), subsidiando as discussões sobre os gêneros do discurso. Ainda metodologicamente, o trabalho possui viés qualitativo e descritivo, seguindo uma perspectiva interpretativa. As reflexões encaminham então, para uma aplicação da proposta, a fim de que alcance resultados, que comprovem a relevância dos projetos de letramento, pelo seu caráter social e, ao mesmo tempo, didático, uma vez que associa eventos e práticas de letramento em situações autênticas de uso da leitura e da escrita. Além disso, por focar em situações reais de uso dos textos com alunos da EJA, constitui um avanço na aprendizagem de novos gêneros, promovendo a criticidade e a consciência sobre como ler, escrever, interagir e mobilizar práticas sociais através da língua(gem) no mundo digital e do trabalho.

Palavras-chave: Leitura. Escrita. Projeto de letramento. Mundo digital. Mundo do trabalho.

ABSTRACT: The school seems not to have followed social changes in people's way of interacting. In the field of work, it is common for individuals to lose job opportunities because they do not know how to write a curriculum and / or how to use digital networks to connect with companies or seek opportunities in this sense,

\footnotetext{
${ }^{1}$ Graduado em Letras - Português (UESPI). Especialista em Libras e Docência do Ensino Superior (FAEME). Mestrando em Letras - Estudos da Linguagem (UFPI). Membro do grupo de pesquisas em Texto, gêneros e discurso (CATAPHORA) e professor na educação básica e ensino superior. E-mail: antonioartursilvacantuario@hotmail.com
} 
because they have weaknesses in reading and writing in the work and in the digital world. Facing this problem, this study presents a discussion about the relevance of the application of literacy projects in the Portuguese Language classroom, focusing on the reading and writing practices of the professional sphere in interface with the digital environment. The proposal is theoretically anchored in the conceptions of literacy and literacy by Kleiman (2007), Soares (2009), Tfouni (1994) and Rojo (2012); Coscarelli (2011), Goulart (2011), Lévy (1999) and Xavier (2010), on digital literacy and teaching practices; and Bakhtin (2011), subsidizing discussions on the genres of discourse. Still methodologically, the work has qualitative and descriptive bias, following an interpretive perspective. The reflections then lead, for an application of the proposal, in order to achieve results, which prove the relevance of the literacy projects, for its social and at the same time didactic character, since it associates events and literacy practices in situations authentic use of reading and writing. In addition, focusing on real situations of using texts with EJA students is an advance in the learning of new genres, promoting criticality and awareness of how to read, write, interact and mobilize social practices through language (gem) in the language digital world and work.

Keywords: Reading. Writing. Literacy project. Digital world. World of work.

\section{CONSIDERAÇÕES INICIAIS}

Com o passar dos tempos, surgem novas formas de ser e agir no mundo, incluindo-se novas formas de linguagens. A era digital é um demonstrativo dessa afirmação, se consideramos que muitos relacionamentos, hoje, são tecidos com o auxílio da web cam, das salas de bate-papo e das redes sociais digitais e, nas relações de trabalho, muitas empresas já fazem pré-seleção pelas redes sociais digitais, como as fan pages.

O ambiente digital, hoje, também funciona como um grande meio de aprendizado, tendo em vista que, em situações específicas, recorremos ao YouTube e/ou sites de ajuda, que ensinam como se comportar, por exemplo, numa entrevista de emprego. No entanto, nem todos os cidadãos sabem operar, adequadamente, com essas novas formas semióticas de leitura e de escrita. Por exemplo, o público alvo da Educação de Jovens e Adultos (EJA), o qual é composta voltada por indivíduos que, por diversos motivos, não puderam iniciar ou continuar seus estudos na modalidade educacional regular, devido a fatores diversos, que revelam as diferenças e as desigualdades sociais nesse país. 
Um passo para mudar essa realidade é a execução de práticas de letramento que preparem o indivíduo para se desenvolver com excelência em diversos campos sociais, pois o letramento não se refere apenas ao fato de saber ler e escrever, mas, saber utilizar essas habilidades de forma satisfatória, a favor de alcançar variados objetivos sociais, como afirmam Soares (2009), Kleiman (2007), Rojo (2012) e Tfouni (1994).

É, pois, com base nessas reflexões, que este artigo discute sobre a possibilidade de implantação de uma proposta de projeto de letramento, envolvendo eventos e práticas de letramentos constantes na relação entre mundo profissional e mundo digital, interligados por meio das práticas de linguagem para atingir uma finalidade real: inserir-se no mercado de trabalho.

Considerando essa realidade, torna-se importante, incluir no currículo escolar, projetos de letramento que partem de práticas sociais no âmbito digital e sua relação com o mundo trabalho, sobretudo, na modalidade de ensino da EJA, uma vez que amplia as oportunidades de os alunos melhor compreenderem e se inserirem no mundo do trabalho, avançando-se no sentido de romper com uma pedagogia estruturalista e centrada apenas no código, como aponta Tfouni (1994).

Muitos alunos da EJA não sabem, por exemplo, como produzir um currículo ou preencher um formulário on-line, na maioria das vezes, por não saberem trabalhar com softwares e hardwares que permitem tal produção, ou não sabem enviar um e-mail, necessitando então, recorrer a outras pessoas, quando encontram, para fazê-lo. Com isso, enfrentam efetivas barreiras no mundo letrado.

É considerando o perfil dessa audiência a qual, em sua maioria, busca o ingresso no mercado de trabalho, que faz-se necessário o desenvolvimento de projetos de letramento no âmbito escolar, no sentido de, além de inseri-los, inclui-los nas redes de relacionamento digital, bem como, ensiná-los a lidar com essa nova forma de se comunicar para também, adentrar com mais destreza, no campo do trabalho, com seus gêneros discursivos específicos que, mais do que nunca, conclama 0 apoio das mídias digitais para realizar suas atividades, desde o recrutamento ao processo de contratação.

Diante dessa conjuntura, o letramento digital possibilita uma maior atuação de jovens e adultos nas relações sociais às quais estão expostos diariamente e poderão atuar em diversos campos sociais, uma vez o letramento possibilita uma reflexão crítica sobre o que se produz, permitindo assim, ao indivíduo se integrar em 
diferentes contextos sociais e culturais, assegurando, dessa forma, a igualdade social e a inclusão na sociedade em que habita.

A discussão apresentada neste trabalho, contribui também, para a formação de pessoas capazes de lidar com ferramentas digitais, possibilitando que elas, além de vivenciar o mundo do trabalho, se envolvam com questões relacionadas à política, a cultura e outras questões de sua cidade, estado ou país, uma vez que, mesmo longe, geograficamente, a internet e os softwares/hardwares promovem a inter-relação entre pessoas, culturas, modos diferentes de agir, rompendo com fronteiras geográficas e permitindo aos internautas, navegar com segurança e inteligência no mundo digital, se devidamente letrados digitalmente.

Como procedimentos metodológicos de construção deste estudo, recorreuse a uma análise bibliográfica sobre a definição de projeto de letramento e seus constituintes, à luz das interpretações de autores de referência na área. Ressalta-se que, o propósito aqui, não é apresentar uma abordagem explícita de uma metodologia de ensino, mas, situar a importância de conceber e aplicar projetos de letramento na escola. Dessa maneira, apresenta-se apenas sugestões sobre um possível projeto a ser aplicado, e, portanto, não tem-se dados coletados em campo, para a apreciação de uma consideração final propriamente dita.

$\mathrm{O}$ artigo encontra-se dividido da seguinte forma: primeiro, traz-se uma abordagem teórica em torno da definição de projeto de letramento, focando nas implicações metodológicas para o ensino, e desdobra-se de forma mais específica em um tópico sobre o letramento digital; segundo, discute-se o projeto de letramento e seu envolvimento com a escola, pontuando alguns aspectos, como, os culturais e sociolinguísticos, estratégias de motivação do alunado no envolvimento com o trabalho, considerações mais específicas dos gêneros do discurso na abordagem didática do trabalho, bem como, um levantamento dos aspectos multimodais e interdisciplinares que circunda a diversidade dos textos escolhidos para compor um projeto de letramento. Destaca-se ainda, um tópico à discussão dos eventos de letramento dentro e fora da escola, que perpassam as etapas do projeto. E, por último, as considerações finais e referências.

\section{LETRAMENTO E SUAS IMPLICAÇÕES TEÓRICO-METODOLÓGICAS}


Sabe-se que o ensino de língua materna que vem se consolidando na contemporaneidade pauta-se numa perspectiva teórica, que compreende a escrita como um artefato linguístico e social, a serviço das pessoas, com propósitos sociais e comunicativos situados em esferas da atividade humana (SOARES, 2009; KLEIMAN, 2007).

Nessa abordagem, emerge uma nova proposta teórico-metodológica de ensinar os indivíduos a ler e escrever, considerando as mudanças que a sociedade vem sofrendo ao longo do tempo. Tudo isso, partindo do fato de que hoje, existem outros modos de dialogar, ultrapassando-se os limites geográficos e pessoais, isto é, as pessoas relacionam-se tanto face a face, como virtualmente, por meio de outros suportes, como a tela do computador, celular, tablet etc.

Essa evolução evoca então, uma mudança nos procedimentos de escrita e leitura, uma vez que outras semioses passam a tecer textos, propósitos e formas de agir socialmente no mundo digital. Os sons, as imagens, as cores e outros recursos próprios da virtualidade, capazes de estabelecer relações dialógicas no interior dos textos, no sentido de considera Kleiman (2007), bem como, entre autor-texto-leitor, conferem aos discursos eletrônicos, um caráter híbrido e peculiar, se considerarmos a tecnologia da escrita impressa.

Para Soares (2009), as atividades de leitura e escrita devem se pautar em práticas sociais que demandam o uso da escrita para cumprir seus propósitos. Segundo a autora, o termo "letramento" aparece em meados da década de 80 no vocabulário brasileiro e provém da palavra inglesa "literacy", que significa a condição ou estado de alguém que aprende a ler e escrever. Mary Kato (1986), Leda Verdiani Tfouni (1988) e Ângela Kleiman (1995) inserem em suas obras, pioneiramente, esse termo, constituindo-se, a partir de então, o "letramento" como termo técnico das áreas da Educação e Ciências Linguísticas.

Tfouni (1994), considerando as práticas de letramento numa abordagem sócio históricas, faz menção a algumas concepções de letramento, desde que linguísticas passaram investigar com mais afinco sobre o termo "literacy".

A primeira perspectiva, chamada de individualista-restritiva, segundo a autora, volta-se apenas aos processos técnicos de leitura/escrita, sendo a escrita vista apenas como código, enquanto que a perspectiva tecnológica, entende o termo "literacy", como um produto situado em contextos de registros de prestígio, sofisticados, encaminhando-se à concepção positivista. 
E, por último, a terceira concepção, dita cognitivista, enfatiza os processos mentais no desenvolvimento da escrita, destacando processos internos e, em contrapartida, desconsiderando os fatores sociais e culturais.

Nessas três abordagens, Tfouni (1994) vê algo familiar: o fato de que atribuem ao termo "literacy", a habilidade de escrita e leitura, focalizando também, o processo de alfabetização que, segundo Soares (2009), faz parte do processo de letramento.

Entende-se, conforme os estudos de Tfouni (1994), Kleiman (2007) e Soares (2009), que o letramento situa a leitura e a escrita social, política e culturalmente. Nessa perspectiva, ser alfabetizado não é o suficiente, mas a formação de sujeitos que se apropriem dessa tecnologia nas práticas sociais, a fim de exercer a cidadania, cabendo à escola se adequar às novas demandas no modo de se comunicar dentro e fora dela.

Nesse sentido, o letramento desencadeia consequências sociais, culturais e linguísticas, pois o indivíduo letrado se relacionará de modo diferente, o seu lugar social e político muda, sua compreensão cultural é alargada, a escrita passa a ter propósitos situados e a oralidade também é influenciada, concebendo falantes conscientes e competentes em sua língua materna.

Rojo (2012) concorda com a concepção de Soares (2009), ao considerar as variedades de eventos de letramento (aspecto social), mas avança quanto a essa noção ao considerar as diversas formas de cultura e semiótica para constituir uma definição do que chama de multiletramento (envolve valores culturais, sentidos heterogêneos que evoca também questões relacionadas à religião e gênero, por exemplo), ancorando essa noção às multiplicidades cultural e semiótica para a arquitetura de textos.

Kleiman (2007) também se alinha à noção de letramento, empreendida por Soares (2009), uma vez que concorda com a ideia de escrita situada socialmente para atingir propósitos comunicativos, numa relação de coletividade, no sentido proposto por Bakhtin (2011), de que todo enunciado deve ser compreendido social e historicamente, construído e significado em relação a outros enunciados, numa relação dialógica e polifônica, com finalidades específicas.

E, por enunciado, concebe-se neste estudo, a definição desenvolvida por Bakhtin (2011), que entende os textos como materializações de um processo linguístico-discursivo, no qual os gêneros discursivos estão a serviço de uma Cadernos Cajuína, V. 4, N. 1, 2019, p.153-172. 
comunidade para determinados fins, isto é, os gêneros são construções sociais relativamente estáveis, que mantém entre tema, conteúdo e estilo um constructo que visa atingir a objetivos sociais e comunicativos de uma sociedade e orientam o modo de ser e agir frente às demandas sociais.

Para subsidiar a proposta de projetos de letramento na escola (eventos de letramento), Kleiman (2007) reitera que ela deve envolver uma coletividade com participantes que agem a partir de seus conhecimentos prévios, com interesses individual e coletivo, situados numa esfera humana da comunicação, ação não tão estranha ao que já fazem as pessoas antes de habitar o contexto escolar.

Assim, a autora considera projeto de letramento, como:

Um conjunto de atividades que se origina de um interesse real na vida dos alunos e cuja realização envolve o uso da escrita, isto é, a leitura de textos que, de fato, circulam na sociedade e a produção de textos que serão realmente lidos, em um trabalho coletivo de aluno e professor, cada um segundo sua capacidade. (KLEIMAN, 2000, p. 238)

Assim, os projetos de letramento devem se pautar num percurso que se inicia com a identificação da prática social em que se inserem os alunos que, por sua vez, determina os gêneros discursivos que dão suporte ao modo como os sujeitos se engajam para cumprir determinados papéis sociais e atingir objetivos comunicativos.

A consideração de Kleiman (2007), nesse sentido, instiga, então, a pensar o papel da escola que, como agente formadora, deve destinar aos alunos, um espaço de interação, onde a prática social seja o ponto de partida para o desenvolvimento da competência linguística, ensinando-os a usar a escrita para atingir objetivos, construir conhecimentos e compartilhar saberes, bem como, torná-los pessoas críticas que saibam conquistar, através da linguagem, o espaço (profissional, acadêmico, político, social etc.) que lhes é de direito.

\subsection{Letramento digital}

Em se tratando dos textos que circulam no universo digital, vê-se um novo modo de ler e escrever: antes, apenas a caneta e o papel, lendo-se da esquerda para a direita, agora, as letras atravessam o mundo virtual, interagindo com outras 
semioses, em tamanhos e tonalidades diferentes, numa leitura dinâmica, não linear, bem como, desencadeando um processo de autoria dessacralizadora, se comparado aos textos da mídia impressa.

Isso implica também, no modo como os indivíduos agem, processam e constroem sentidos socialmente. Essa evolução da escrita exige novas habilidades, como, por exemplo, ciclar, teclar, compartilhar, ler com várias janelas de navegação, usar atalhos para unir letra à imagem, estabelecer links etc.

Sobre as novas possibilidades de construção de sentido no oceano digital e a noção de hipertextualidade, Xavier (2010, p. 208-209) enfatiza o seguinte:

\begin{abstract}
Por hipertexto, entendo uma forma híbrida, dinâmica e flexível d linguagem que dialoga com outras interfaces semióticas, adiciona e acondiciona à sua superfície formas outras de textualidade. [...] $\mathrm{Na}$ esteira da leitura do mundo pela palavra, vemos emergir uma tecnologia de linguagem cujo espaço de apreensão de sentido não é apenas composto por palavras, mas, junto com elas, encontramos sons, gráficos, e diagramas, todos lançados sobre uma mesma superfície perceptual, amalgamados uns sobre os outros, formando um todo significativo e de onde os sentidos são complexicamente disponibilizados aos navegantes do oceano digital. (Grifos do autor)
\end{abstract}

O autor evidencia que, além de o espaço digital propiciar outras formas de linguagens, é necessário ainda, uma preocupação com a noção de textualidade que se desdobra, dentre outros aspetos, nos processos de escrita dos textos, claro, reconfigurada e com outras possibilidades de exibição, já que, o próprio autor compreende a necessidade e a presença da palavra, junto à outras semioses, no mundo digital.

Em vista disso, o ambiente digital é um suporte que está incorporando várias esferas da comunicação e, com isso, seus respectivos gêneros discursivos, a exemplo dos gêneros da esfera trabalhista, como currículo vitae, o formulário online, o e-mail e as fan pages de lojas que, por vezes, usam esse espaço para recrutar mão de obra.

Esse processo de reconfiguração do suporte, exige dos indivíduos, um preparo técnico para escrever na tela, bem como, construir sentidos no interior desses gêneros, considerando que, por exemplo, o currículo vitae (que deve ser, obrigatoriamente, digitado) e o e-mail só ganham vida no interior das máquinas de informática com ou auxílio de softwares de texto. 
Pereira (2011, p. 15) afirma que os novos aparatos tecnológicos são importantes instrumentos para se ensinar a ler e escrever, no entanto, ressalta que no processo de situar a leitura e a escrita socialmente, no ambiente digital, vai além de aprender a usar, por exemplo, as teclas de um computador. O autor considera também, que a informática tem propiciado uma popularização no acesso a conteúdos diversificados, "mas não necessariamente em inclusão social".

Diante disso, pode-se inferir que nem todos, embora com acesso à internet (sobretudo, no campo do trabalho, que depende em boa parte dos suportes digitais para construir seus gêneros) estão "inseridos" no mundo digital, ou seja, interagem e se engajam com outros participantes, com direitos iguais. Logo, se a informática está sendo democratizada, mas nem todos estão inseridos nessa prática, é de fundamental importância o letramento digital, sobretudo, nas escolas brasileiras.

O letramento digital é, então, uma condição ou estado de ler e escrever na cibercultura, como consideram Coscarelli (2011) e Soares (2009), onde os indivíduos passam, de fato, a participar e interagir com outras pessoas e culturas diferentes via textos multimodais, o que altera, por sua vez, o estado ou condição dessas pessoas frente à tecnologia da escrita e à leitura. Para isso,

Precisamos dominar a tecnologia da informação, estou me referindo a computadores, softwares, internet, correio eletrônico, serviços, etc., que vão muito além de aprender a digitar, conhecer o significado de cada tecla do teclado ou usar um mouse. Precisamos dominar a tecnologia para que, além de buscarmos a informação, sejamos capazes de extrair conhecimento. (PEREIRA, 2011, p. 17)

O autor diz então, que saber manipular as ferramentas digitais não é suficiente para produzir conhecimentos e, mediante essa afirmação, é que o letramento digital pode promover essa mudança na condição ou estado dos indivíduos que lidam com essas tecnologias, rompendo-se também, com a exclusão social (no campo do trabalho, por exemplo), a fim de que a sociedade, de um modo geral, tenha acesso aos conteúdos digitais e, com eles, dialogue de maneira crítica.

Para que alunos tenham acesso a informações com segurança, no universo digital, é preciso que os professores estejam preparados para lidar com essa situação, ou seja, que se qualifiquem na tentativa de se letrar digitalmente, a fim de proporem recomendações de ensino que, além de criativas, desenvolvam linguística, 
social e cognitivamente as gerações de hoje para que as do amanhã também estejam engajadas na comunidade digital, ou seja, incluídas digitalmente.

Coscarelli (2011, p. 29) aponta que "[...] agora é preciso saber digitar, é preciso conhecer as fontes disponíveis no computador e como usá-las.". Ainda não precisamos trocar o lápis e a caneta pelo teclado, mas devemos aceitar essa troca como algo previsto para um futuro próximo". É então, para a autora, necessário que os alunos aprendam a digitar, mas também, que saibam produzir com essa ação, um conhecimento que supra suas necessidades sociais e comunicativas.

Para a autora, a máquina (o computador) por si só, não faz muita coisa, mas é dever do professor estudar e se preparar para mediar o contato entre o ambiente digital e os educandos, a fim de que eles aprendam, por exemplo, a produzir um email, um formulário on-line, um comentário em redes sociais. Assim, para que a rotina desses gêneros discursivos (que ganham vida no espaço digital) seja cumprida, os alunos devem lidar com muitos elementos semióticos, a exemplo dos emotions, que cumprem um papel importante para estabelecer uma interação quase que presencial entre os internautas. Logo, o mundo digital possibilita aos discentes,

\footnotetext{
Navegar na internet, por sua vez, nos possibilita acessar muitos textos e gêneros variados, ao mesmo tempo, por meio de links que vamos acessando: um texto se abre, então, em muitos textos, operacionalmente, e não mais só em nível metafórico, se relacionarmos à leitura de textos escritos em papel. Essa possibilidade nos faz experimentar o conhecimento de um modo novo, diferente das fontes tradicionais de referência. (GOULART, 2011, p. 54)
}

Disso, compreende-se que no ambiente digital há muito mais que palavras que formam frases, que constroem textos, mas, há uma cadeia hipertextual, capaz de conectar ao mesmo tempo, com várias janelas na tela do computador, celular ou tablet, sem trocar de página, textos híbridos, numa quebra sequencial, em que um único link pode subsidiar um universo de leituras múltiplas. É nesse momento, que o letramento digital permite aos leitores perpassar por caminhos coerentes para que as estruturas verbais e não verbais façam sentindo naquele contexto.

Desse modo, pode-se perceber um forte elo entre o mundo do trabalho e o mundo virtual, haja vista, a diversidade de discursos que o suporte digital pode contemplar, entre eles, os enunciados próprios da área trabalhista; e dar 
dinamicidade aos gêneros discursivos que, por vezes, são transmutados de seu suporte natural para o mundo cristalizado.

É nessa perspectiva de letramento, inscrita nas postulações de Bakhtin (2011), sobre gênero discursivo; Soares (2009), em diálogo com as contribuições de Rojo (2012), sobre multiletramentos; e Tfouni (1994), sobre as concepções de letramento; Kleiman (2007), enfocando aspectos metodológicos sobre eventos de letramento; Pereira (2011), Coscarelli (2011) e Goulart (2011), dialogando sobre o letramento em contexto digital; e Xavier (2010) e Lévy (1999); contextualizando sobre novas formas de linguagem no oceano digital e o hipertexto, que apresenta-se a seguir, um desenho ou proposta de projeto de letramento, em uma visão ainda que apenas teórica, mas com vistas ao desenvolvimento de atividade escolares.

\section{PROJETO DE PRÁTICAS DE LETRAMENTO EM SALA DE AULA}

Em linhas gerais e partindo de um desenho teórico, mas com viés aplicado, apresenta-se, neste tópicos, aspectos relevantes de serem considerados na formulação e execução de um projeto de práticas de letramento em sala de aula.

\subsection{Aspectos culturais e sociolinguísticos implicados em um projeto de letramento}

Cada vez mais surgem inovações tecnológicas, que estão rotineiramente presentes em nosso cotidiano e que implicam diretamente no surgimento de novos aspectos socioculturais, mas é notório o fato de que, por motivos diversos, não de modo generalizado, o acesso a essas tecnologias ainda parece restrito a algumas instâncias sociais, como exemplo da EJA.

Partindo disso, essa proposta visa a inclusão sociocultural e econômica do indivíduo no mundo do trabalho e no mundo digital, onde os limites culturais são ainda mais alargados, pois, vivemos parte de nossas rotinas atualmente, na cibercultura, termo cunhado por Lévy (1999, p. 17), para designar o "conjunto de técnicas (materiais e intelectuais), de práticas, de atitudes, de modos de pensamento e de valores que se desenvolvem juntamente com o crescimento de ciberespaço". 
Dessa forma, através do letramento digital o sujeito poderá compreender as linguagens geradas pelos novos meios de comunicação digital e será capacitado para desempenhar inúmeras funções no âmbito das tecnologias digitais exigidas pelo mercado de trabalho.

Apesar das dificuldades que há em se lidar com o letramento digital, principalmente o público da EJA, em que muitos já vêm de uma série de desmotivações, é necessário que o professor seja capacitado para lidar com as novas tecnologias e assim, promover a interação entre tecnologia e o seu alunado, pois é necessário que esse público seja incluído na cultura digital propiciada pelos novos meios de comunicação, no contexto da cibercultura.

Tendo em vista as transformações e o surgimento de novas formas de linguagem ao longo dos tempos, Faraco $(2004$, p. 02$)$ afirma que

Cabe ao ensino ampliar a mobilidade sociolinguística do falante (garantir-lhe um trânsito amplo e autônomo pela heterogeneidade linguística em que vive) e não concentrar-se apenas no estudo de um objeto autônomo e despregado das práticas socioverbais (o estrutural em si).

Desse modo, é necessário que os alunos da EJA estejam imersos na cultura digital que, por sua vez, dialoga com os aspectos culturais relacionadas ao mundo do trabalho (por exemplo, na relação estabelecida entre empresa e funcionários, ética etc.). E para lidar com essa situação, o uso adequado (ao gênero) de registros formais (currículo vitae, formulário on-line) e informais (tutoriais, fan page) da linguagem serão necessários, uma vez que a língua deve ser vista e usada em função de propósitos comunicativos específicos em contextos situados.

Além disso, alguns gêneros do mundo do trabalho, como o currículo vitae exige um trabalho cuidadoso com a relação intertextual, de acordo com os requisitos propostos pela empresa em listas de recrutamento e entrevistas de emprego.

$\mathrm{E}$, considerando que o currículo vitae é um gênero marcado pela brevidade, objetividade, deixando evidente a imagem do candidato e sua relação com o previsto pela empresa, deve estabelecer informações em forma de tópicos, o que não exige com frequência o uso das conjunções, o trabalho com o uso de períodos simples e de orações coordenativas assindéticas, quando se considera as características estilísticas e composicionais do referido gênero. 
O estudo das escolhas lexicais também deve ser pauta de conteúdo, já que, cada esfera da comunicação humana, de acordo com Bakhtin (2011), elabora seus enunciados relativamente estáveis, ou seja, se há uma estabilidade dos enunciados, há recorrências lexicais próprias e que ajudam a identificar determinados discursos de suas respectivas comunidades discursivas. A distribuição de informação e a organização fraseológica, em sua maioria, com períodos curtos e bastante objetivos, também são pertinentes ao roteiro de conteúdos contemplados pelo projeto.

A linguagem de especialidade/técnica também recorre na proposta, como um indício de trabalho com os aspectos sociolinguísticos, tendo em vista que, no preenchimento de um formulário on-line ou o envio de um e-mail, o usuário tem que ler outras semioses, como vídeos de instrução e barras de acesso, que têm um léxico específico e com formatos digitalizados, no caso do formulário; bem como, o uso de atalhos, que têm nomes característicos, por vezes, bastante técnicos. No mundo do trabalho, o registro formal da escrita também se apresenta como necessário à construção dos gêneros que circulam nessa esfera.

A oralidade e sua relação com a escrita também é elencada nesta atividade, já que a entrevista de emprego, diretamente relacionada ao currículo, é oralizada com base no que se diz no currículo, ou seja, há uma relação de ajuda entre escrita e fala e não duas modalidades rivais, no sentido de que afirma Marcuschi (2008), ao propor que fala e escrita se intercambiam como modos particulares e, ao mesmo tempo, interrelacionados nas formas de representar os discursos.

$\mathrm{E}$, conforme orientam todas as diretrizes curriculares de ensino, é necessário preparar o aluno para vivenciar diferentes esferas de atividade, como a esfera do trabalho. Atendendo a esse fim, um projeto de letramento, encabeça uma oportunidade de unir cultura digital a cultura das relações de trabalho, bem como, o uso dos gêneros discursivos que transitam nesses setores relacionais, numa interface com as convenções de escrita, ortografia e acentuação, conhecimentos gramaticais também necessários à formação da referida audiência da proposta pedagógica de um projeto de práticas de letramento em sala de aula.

\subsection{Estratégias gerais para promover a motivação e a adesão dos alunos a um projeto de letramento}

Estratégias motivacionais a serem desenvolvidas com os alunos da EJA: 
- Atividades de pesquisa de campo, em uma empresa, sobre o mundo do trabalho, sobre os processos seletivos de contratação e a investigação de empresas que estão realizando contratação;

- Dramatização de uma entrevista de emprego (LIMA; FERNANDES, 2014); ${ }^{2}$

- Estudo dirigido sobre as novas tecnologias no mundo do trabalho e sobre a importância da informática hoje;

- Palestras com os profissionais da informática e análise de sistema de empresas e/ou gerente e Recursos Humanos $(\mathrm{RH})$ e um profissional da área que os alunos mais se identifiquem;

- Apresentação de vídeos: reportagens ou palestras sobre o mercado de trabalho e a informática.

\subsection{Definição do tratamento a ser dado aos gêneros envolvidos no desenvolvimento de um projeto de letramento}

Sugere-se, como possibilidades de trabalho, os seguintes gêneros: currículo vitae, formulário on-line, e-mail, entrevista de emprego (gêneros para ler e escrever); tutorial sobre entrevista de emprego e fan page de lojas (gêneros como apoio de leitura e de produção dos gêneros anteriores).

Considera-se que o tratamento dado a esses gêneros se inscreve numa perspectiva sociointeracionista que os vê como formas maleáveis disponíveis a pessoas e a propósitos específicos, e que, de fato, se materializam em situações concretas de uso.

Assim, na sequência de estudo e produção desses gêneros leva em consideração um conjunto de exemplares para leitura, no intuito de que os alunos reconheçam tema, estilo e estrutura peculiares a esses discursos, como forma também, de guiar a produção inicial dos textos, a qual deve ser discutida entre os colegas e reescrita de acordo com as considerações feitas pelo professor em

\footnotetext{
${ }^{2}$ Trata-se de um projeto elaborado por Lima; Fernandes (2014), como trabalho de conclusão do curso "Caminhos da escrita", oferecido pelo Cenpec. Na ocasião, os alunos pesquisaram e aprofundaram seus conhecimentos sobre a profissão com a qual tinham afinidade e encenaram, coletivamente, a rotina desse profissional, falando também como as pessoas nesse ramo lidam com o campo do trabalho peculiar a suas respectivas especialidade.
} 
parceria com a turma, culminando numa versão final, destinada a alguma instituição que esteja em processo de seleção.

E, para guiar a temática proposta à produção, levar-se-á à sala de aula debates, seminários, entrevista e reportagens/tutoriais, com as devidas considerações do professor, no sentido de ajudar os alunos a se apropriarem desses gêneros catalizadores (SIGNORINI, 2006), como forma de integrar toda a sequência didática.

\subsection{Levantamentos da multimodalidade a que a prática de letramento submete todos os textos trabalhados em um projeto de letramento}

Por estarem situados num suporte que permite outras formas de construir sentido, os gêneros propostos ultrapassam os limites do essencialmente escrito:

- No currículo, o uso da autoimagem (fotografia 3x4) é um recurso visual exigido por algumas empresas e que se relaciona com as normas de imagem da instituição e com as informações pessoais prestadas no topo da folha do currículo;

- O formulário on-line, geralmente, traz ícones de formatação do texto, como tamanho da fonte e estilo, além de possuir mecanismos hipertextuais, como páginas de ajuda de preenchimento, por exemplo;

- O e-mail, além de suportar o escrito, também permite que se anexe documentos, imagens etc., bem como, uma barra de ícones de formatação do texto;

- A entrevista privilegia a oralidade, em relação com o texto verbal e com a própria linguagem corporal, já que se espera, nesse gênero, um modo de agir fisicamente coerente com o que se diz no currículo;

- O tutorial e a fan page contêm o verbal, imagens, sons, animações, chamando mais atenção dos internautas e tornando mais dinâmica a leitura do conteúdo veiculado.

\subsection{Investigação sobre as possibilidades de integração de um projeto de} letramento da área de Língua Portuguesa com outras disciplinas do currículo 
O foco interdisciplinar da proposta deve articular o máximo possível de componentes curriculares. No caso aqui exemplificado, além da Língua Portuguesa, não se pode deixar de fora, a disciplina de Informática, Sociologia e Língua Inglesa.

A Informática, pelo aproximação pedagógica e orientada que ela possibilita entre o aluno e o mundo das ferramentas tecnológicas, utilizando-se destas, como mecanismos de construção de aprendizagens múltiplas e colaborativas.

A Sociologia, porque é ela quem procura instigar os alunos a refletir sobre seu papel dentro da sociedade e da cibercultura como indivíduo e cidadão, bem como, discute as relações de trabalho ao longo do tempo, para que assim, os discentes tenham uma visão crítica sobre os papéis sociais em instâncias trabalhistas.

A Língua Inglesa está bastante presente no meio digital, uma vez que várias ferramentas e programas da internet têm nomenclaturas em inglês. Por isso, é bom estar familiarizado com certos termos, a fim de saber bem sua funcionalidade.

Assim, o projeto de letramento possibilita uma interação entre disciplinas bastante importantes para a formação do aluno, que tem a oportunidade de utilizar conhecimentos adquiridos ao longo da sua vida escolar, alinhando finalmente, disciplinas que antes Ihes parecia dissociada uma das outras.

\subsection{Eventos de letramento decorrentes do trabalho com projetos de letramento dentro e/ou fora do ambiente escolar}

- Eventos fora da escola: Os alunos podem fazer uma visita técnica a uma empresa para adentrar no mundo do trabalho, bem como, as novas formas de contratação, entendendo como esse processo funciona. Além de pesquisar sobre as empresas que estejam em processo de seleção, cujo envio do currículo e formulário sejam disponibilizados no ambiente digital, uma vez que os textos a serem produzidos necessitam circular em sua esfera de atividade da comunicação humana recorrente.

- Eventos na escola: Os alunos podem participar de uma palestra com profissionais atuantes no mercado de trabalho nas áreas em que eles mais se identificarem, bem como, assistir vídeos e reportagens relativos ao mercado de trabalho e uma dramatização em que eles 
possam ver, com mais nitidez, como se procede a uma entrevista de emprego; estudos dirigidos, seminários e debates sobre a referida temática também estão inseridos no escopo de atividades dentro da escola, a fim de que haja uma apropriação da temática e da composição dos gêneros a ser produzidos.

\subsection{Avaliação dos trabalhos de uma proposta de projeto de letramento}

No processo avaliativo são considerados desde os conhecimentos técnicos, até mesmo, os aspectos motivacionais, tentando verificar se, de fato, os alunos se engajaram e se os conhecimentos foram condizentes com seus modos de agir.

O grau de apropriação do eixo temático e da composição dos gêneros também compõem aspectos a serem avaliados, bem como, o processo evolutivo da escrita dos discentes, comparando as versões inicial e final, já que os textos produzidos são encaminhados a uma empresa, também como forma de avaliação.

A autoavaliação é também adequada para o processo, considerando que no mundo do trabalho, cada experiência exige que os indivíduos revejam que atitudes devem ser incorporadas ou que aspectos precisam revistos para um bom desenvolvimento no mercado de trabalho, sendo esta uma forma de já treinar esses alunos para essa realidade necessária no mundo de hoje.

A avaliação coletiva em que uma equipe avalia a outra, no processo de escrita e reescrita, guiada por um formulário desenvolvido pelos docentes também é útil também, pois leva em conta não só a opinião do professor, mas as pontuações feitas pelos alunos.

São esses, alguns dos instrumentos de verificação de aprendizagem que podem ser explorados na aplicação de uma proposta pedagógica dessa natureza, considerando para cada método, o desenvolvimento dos alunos e a postura do próprio professor no prosseguimento das atividades.

\section{CONSIDERAÇÕES FINAIS}

Esse trabalho objetivou apresentar a importância de aplicação de propostas de um projeto de letramento, no contexto de ensino e aprendizagem da EJA, considerando as práticas letradas digitais (letramento digital) presentes no mundo do 
trabalho, com vistas a futura atuação profissional do sujeito. O intuito era, então, vislumbrar as contribuições pertinentes de um projeto de letramento no contexto curricular das aulas de língua materna, de modo a oportunizar aos alunos o contato autêntico com textos, refletindo o uso da linguagem na mediação de finalidades sociais, como é conquistar um espaço no mercado de trabalho.

É preciso ressaltar, ainda, que a proposta aqui apresentada tem um viés apenas teórico (mas com perspectivas de aplicação), fundamentada nas definições de letramento, vistas em Kleiman (2007) e Soares (2009) e nos procedimentos estruturais, conteudísticos e de desenvolvimento de um projeto de letramento, inspirados no trabalho de Lima; Fernandes (2014). Pontua-se isso, para que não se confunda a ideia primeira do projeto de letramento e da teoria de letramento, que de algum modo, está imbuída nas concepções e práticas desencadeadas por um projeto de letramento. O foco é muito mais prático que teórico.

Assim, percebeu-se na abordagem de um projeto de letramento, que há uma vinculação à corrente sociointerativista da linguagem, considerando essa prática para além da atividade de representação, mas de uso social e real, no cumprimento das demandas sociais, cada vez mais evoluída no transcorrer dos tempos. Isso implica dizer que a complexidade da linguagem acompanha o curso do desenvolvimento de uma sociedade.

Nesse sentido, é via gêneros discursivos que os indivíduos materializam objetivos e se inserem em práticas comunicativas de leitura e escrita cada vez mais complexas, como são nas esferas do mundo profissional e do mundo do trabalho. E, é nesse ponto, que os projetos de letramento podem aproximar ensino, linguagem e finalidades para além do mundo escolar, viabilizando conhecimentos curriculares a conhecimentos de mundo e práticas rotineiras, como é conseguir um emprego, sobretudo, no contexto dos alunos da EJA, que buscam formação rápida para inserção no mercado de trabalho.

Há a possibilidade também, de os alunos ampliarem o repertório de gêneros, tornando-se mais competentes no processo de leitura e produção deles, considerando aspectos formais e funcionais atrelados aos contextos específicos de uso, bem como, da associação crítica na relação entre um gênero e outro.

O projeto de letramento promove também, uma reconfiguração pedagógica no fazer do professor, pois situa sua posição de mediador, estabelece diretrizes coletivas e construtivistas de ensino, priorizando a interação para a construção e 
ampliação de conhecimentos, já que os alunos entram na escola com alguma bagagem ampliada ou não.

A escola também assume um papel diferente, na perspectiva do projeto de letramento, porque permite estreitar os diálogos com a sociedade e considera, nesse aspecto, a heterogeneidade social, linguística e cultural. Além disso, redimensiona na direção de um currículo escolar flexível, interdisciplinar e ampliado.

À guisa de qualquer prescrição impositiva ou interpretação esgotada, a perspectiva de um projeto de letramento e suas propostas metodológicas têm avançado no sentido de permitir que as aulas de Língua Portuguesa não se tornem apenas um palco de normatizações, mas, um ambiente de análise linguística, partindo-se do que os alunos já sabem sobre sua língua e extrapolando os limites da frase, rumo a textos reais e autênticos, a fim de se constituírem (os alunos) como cidadãos capazes de exercer sua cidadania via linguagem.

\section{REFERÊNCIAS}

BAKHTIN, Mikhail. Estética da criação verbal. Tradução Paulo Bezerra. 6. ed. São Paulo: Martins Fontes, 2011.

COSCARELLI, Carla Viana. Alfabetização e letramento digital. In: COSCARELLI, Carla Viana; RIBEIRO, Ana Elisa (Org.). Letramento digital: aspectos sociais e possibilidades pedagógicas. 3. ed. Belo Horizonte: Ceale; Autêntica, 2011. p. 25-40.

FARACO, Carlos Alberto. Por uma pedagogia da variação linguística. In: II CIEL Ciclo de Eventos em Linguística, Universidade Estadual de Ponta Grossa (Paraná), outubro de 2004, p. 01-11. Disponível em: < https://variacaolinguistica.files.wordpress.com/2011/06/faracopor uma pedagogia da variacao linguistica1.pdf >. Acesso em: 20 out. 2018.

GOULART, Cecília. Letramento e novas tecnologias: questões para a prática pedagógica. In: COSCARELLI, Carla Viana; RIBEIRO, Ana Elisa (Org.). Letramento digital: aspectos sociais e possibilidades pedagógicas. 3. ed. Belo Horizonte: Ceale; Autêntica, 2011. p. 41-58.

KATO, Mary. No mundo da escrita: uma perspectiva psicolinguística. São Paulo: Ática, 1986.

KLEIMAN, Angela B. (Org.). Os significados do letramento: uma nova perspectiva sobre a prática social da escrita. Campinas: Mercado de Letras, 1995. 
. Letramento e suas implicações para o ensino de língua materna. Signo (UNISC. Online), v. 32, p. 1-25, 2007.

. O processo de aculturação pela escrita: ensino da forma ou aprendizagem da função? In: KLEIMAN, Angela B.; SIGNORINI, I. (Orgs.). 0 ensino e a formação do professor: alfabetização de jovens e adultos. Porto Alegre: Artmed, 2000. 248. p. 223-243.

LÉVY, Pierre. Cibercultura. São Paulo: Editora 34, 1999.

LIMA, Jária Suéldes Alves de; FERNANDES, F. A. M. Projetos de letramento: desenvolvendo práticas de escrituras em sala de aula. 2014. (Curso de curta duração ministrado/Outra).

MARCUSCHI, Luiz Antonio. Produção textual, análise de gêneros e compreensão. São Paulo: Parábola, 2008.

PEREIRA, João Thomaz. Educação e Sociedade da informação. In: COSCARELLI, Carla Viana; RIBEIRO, Ana Elisa (Org.). Letramento digital: aspectos sociais e possibilidades pedagógicas. 3. ed. Belo Horizonte: Ceale; Autêntica, 2011. p. 13-24.

ROJO, Roxane. Pedagogia dos multiletramentos: diversidade cultural e de linguagens na escola. In: ROJO, R. H. R.; MOURA, E. (Org.). Multiletramentos na Escola. São Paulo: Parábola, 2012. p. 11-31.

SOARES, Magda. Letramento: um tema em três gêneros. Belo Horizonte: Autêntica, 2009.

SIGNORINI, Inês (Org.). Gêneros catalisadores, letramento e formação do professor. São Paulo: Parábola, 2006.

TFOUNI, Leda Verdiani. Perspectivas históricas e a-históricas do letramento. Caderno de estudos linguísticos, Campinas, v. 26, p. 49-62, Jan./Jun. 1994.

Adultos não alfabetizados: o avesso do avesso. Campinas: Pontes, 1988.

XAVIER, Antonio Carlos. Leitura, texto e hipertexto. In: MARCUSCHI, Antônio Luiz; XAVIER, Antonio Carlos. (Org.). Hipertexto e gêneros digitais: novas formas de construção de sentido. São Paulo: Cortez, 2010. p. 207-220. 